\title{
Effectiveness of Hair Care Products Containing Placental Growth Factor for the Treatment of Postpartum Telogen Effluvium
}

\section{Je Yeon Byeon ${ }^{1}$, Hwan Jun Choi ${ }^{1}$, Eun Soo Park ${ }^{2}$, Jin Young Kim ${ }^{2}$}

${ }^{1}$ Department of Plastic and Reconstructive Surgery, Soonchunhyang Cheonan Hospital, Soonchunhyang University College of Medicine, Cheonan; ${ }^{2}$ Department of Plastic and Reconstructive Surgery, Soonchunhyang Bucheon Hospital, Soonchunhyang University College of Medicine, Bucheon, Korea
This work was supported by the Soonchunhyang University Research Fund.

No potential conflict of interest relevant to this article was reported.

\begin{abstract}
Background Postpartum telogen effluvium refers to a phenomenon in which some hair in the growth phase progresses rapidly to the resting phase, which leads to excessive hair loss. This causes a high level of psychological stress. Therefore, an increasing number of women are seeking treatment for this condition.

Methods The subjects of this study were postpartum women in the age range of 20 to 40 years who visited a university hospital between June 2015 and May 2016. Seven patients out of a total of 25 subjects were excluded, and their final follow-up visits were not performed because they found it difficult to return for the follow-up. After screening before delivery, the subjects were provided with hair care products. They visited the hospital 1 week, 1 month, and 3 months after giving birth. During each visit, the hair density and thickness were measured by photographing with a camera and using Folliscope ${ }^{\circledast}$ (Aram Huvis Corporation, Seoul, Korea).

Results The hair thickness at the V-point improved from $0.089 \mu \mathrm{m}$ at the baseline to $0.094 \mu \mathrm{m}$ after using the shampoo for 3 months $(P=0.028)$, and the hair density at the P-point increased significantly, from $75.24 / \mathrm{cm}^{2}$ at the baseline to $81.33 / \mathrm{cm}^{2}$ after using the shampoo for 3 months $(P<0.001)$.

Conclusions In this study, a shampoo and a tonic in which the main material was horse placental growth factor combined with various materials, such as pumpkin extract, panthenol, and niacinamide, were clinically applied.
\end{abstract}

Keywords Alopecia, Cucurbita, Niacinamide, Placeta growth factor, Postpartum period

\section{INTRODUCTION}

In humans, 5 million hair follicles are generally formed during the prenatal stage, of which approximately 100,000 are found on the head. After birth, new hair follicles do not form; only the size of the

Received: Jan 1, 2017 Revised: Feb 6, 2017 Accepted: Feb 20, 2017 Correspondence: Eun Soo Park Department of Plastic and Reconstructive Surgery, Soonchunhyang Bucheon Hospital, Soonchunhyang University College of Medicine, 170 Jomaru-ro, Wonmi-gu, Bucheon 14584, Korea. E-mail: peunsoo@schmc.ac.kr

Copyright () 2017 The Korean Society for Aesthetic Plastic Surgery.

This is an Open Access article distributed under the terms of the Creative Commons Attribution Non-Commercial License (http://creativecommons.org/licenses/by-nc/4.0/) which permits unrestricted non-commercial use, distribution, and reproduction in any medium, provided the original work is properly cited. $\quad w w w . e-a a p s . o r g$ hair follicles, which is under the influence of androgen, changes. Hair does not keep growing indefinitely, but has a lifespan that consists of repeated processes of hair growth and hair loss, which is called the hair growth cycle. The hair growth cycle is broadly divided into the growth phase (anagen), regression phase (catagen), and resting phase (telogen) [1].

Postpartum telogen effluvium refers to a phenomenon in which some hair in the growth phase progresses rapidly to the resting phase, which leads to excessive hair loss. The progress of hair loss involves the whole region of the scalp, in which not only is the hair density reduced, but the hair also becomes thinner. In most cases, this condition is known to begin 2 to 5 months after a woman gives birth $[2,3]$. Because it causes a high level of psychological stress, an increasing number of women are seeking treatment for this condition [4]. 
Various studies on hair loss in general and its treatment are ongoing, but research on postpartum hair loss and its treatment in particular is lacking. Although thyroid supplementation [5], topical progesterone or estrogen lotions, and oral contraceptives [6] are currently used for the treatment of postpartum hair loss, there are concerns regarding their efficacy.

Therefore, we conducted a prospective study in which female subjects who had recently given birth and used hair care products that contained placental growth factor (PlGF) [7] from horses as their main constituent, along with various other nutrients such as pumpkin extract [8], panthenol, and niacinamide [9], which is known to be an effective material in the treatment of hair loss, were observed in follow-up visits.

\section{METHODS}

The subjects of this study were postpartum women in the age range of 20 to 40 years who visited a university hospital between June 2015 and May 2016, and conformed to the ethical guidelines of the 1975 Declaration of Helsinki. This study was conducted on patients who consented not to use any other special hair product or other type of hair care and to maintain the same hair style during the study period. Twenty-five patients participated in this study. This study was designed as a prospective study without a control group.

Exclusion criteria: The following individuals were excluded from the study: patients with particular diseases or conditions that could confound the study results or lead to additional risks, patients with a serious problem that was found during the pre-test or examination, patients who were taking or had recently taken other medica- tions that could alter the effects of the considered products, patients with scalp wounds or scalp/hair diseases, or who had undergone hair transplant and scalp reduction procedures within the previous 6 months, and patients who used pigments/hair dye or had remaining traces of dye in their hair.

Seven of the abovementioned 25 subjects were excluded, and their final follow-up visits were not performed, as they found it difficult to return for the follow-up for reasons such as geographical distance.

The instructions for the use of the hair care products were as follows: After soaking the hair and scalp thoroughly with warm water, apply 3 to $5 \mathrm{~mL}$ of the hair product and massage the scalp evenly. After washing and drying the hair, spray the hair tonic evenly in the region of hair loss, massage gently for 1 to 2 minutes with the fingers, and leave it in. Patients were instructed to use the products on their scalps 2 to 3 times a day.

After screening before delivery, the subjects were provided with $300 \mathrm{~mL}$ of the shampoo and the hair tonic that contained PIGF, pumpkin extract, panthenol, and niacinamide. They visited the hospital 1 week, 1 month, and 3 months after giving birth, for a total of 4 visits including the screening visit. During each visit, hair density and thickness were measured by photographing with a Folliscope and using the Folliscope 2.8 software (LeadM Corporation, Seoul, Korea) [10,11]. After the region with hair loss was combed to ensure that this entire region could be seen, first, pictures were taken with a camera, and, second, pictures of the V-point (the intersection of the coronal line and the mid-sagittal line connecting both tips of the helix) and the P-point (the intersection of the horizontal line and the posterior mid-sagittal line connecting the ear
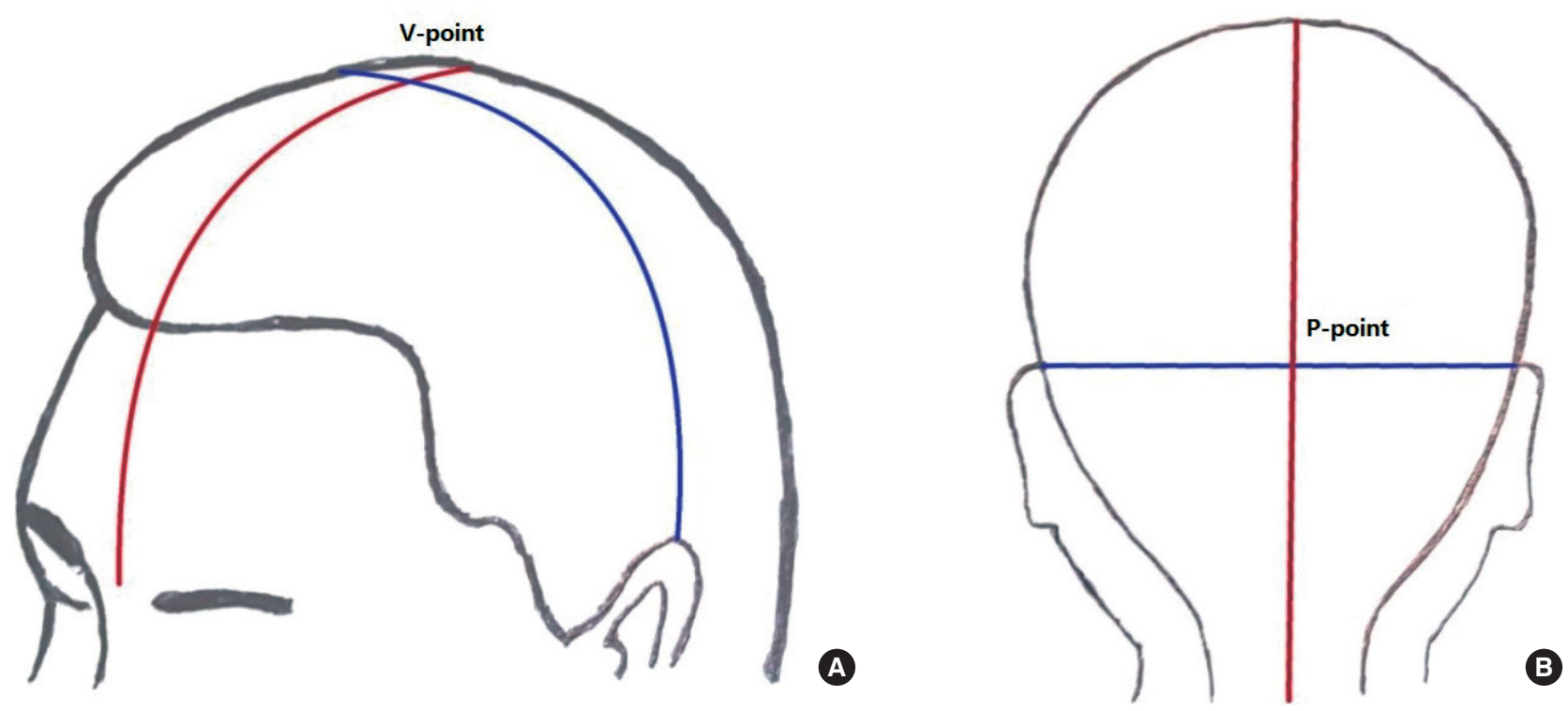

Fig. 1. (A) V-point mean Intersection of the coronal line and the mid-sagittal line connecting both tips of the helix. (B) P-point mean Intersection of the horizontal line and the posterior mid-sagittal line connecting the ear roots. 
roots) of the patients were taken (Fig. 1). The details were recorded. The V-point and the P-point were selected for their reproducibility. The subjects also filled out a questionnaire regarding subjective satisfaction and a safety assessment.

\section{RESULTS}

The average age of the 25 participants in this study was 32.72 years (range, 27-40 years). Of the 25 participants, 15 were primiparae, accounting for $60 \%$ of the sample group, and 10 were pluriparae, accounting for the remaining $40 \%$. The average hair density and thickness at the $V$-point were $79.28 / \mathrm{cm}^{2}$ and $0.089 \mu \mathrm{m}$, respectively, and the average hair density and thickness at the P-point were 75.24/ $\mathrm{cm}^{2}$ and $0.085 \mu \mathrm{m}$, respectively (Table 1 ). Twenty-five subjects visited at week 1, 22 subjects visited at 1 month, and 18 subjects filled out the final questionnaire at 3 months post-delivery.

The time point of the screening before delivery was used as the baseline. Follow-up visits for the observation of the V-point and the P-point of the subjects were performed at 1 week, 1 month, and 3 months after delivery. The results showed that both the hair thickness and the hair density had improved (Fig. 2 and 3) as a whole. The hair thickness at the V-point improved from $0.089 \mu \mathrm{m}$ at the baseline to $0.094 \mu \mathrm{m}$ after using the shampoo for 3 months $(\mathrm{P}=$ 0.028 ), and the hair density at the P-point increased significantly from $75.24 / \mathrm{cm}^{2}$ at the baseline to $81.33 / \mathrm{cm}^{2}$ after using the sham-

Table 1. Baseline characteristics of all subjects

\begin{tabular}{lc}
\hline Variable & Total $(\mathrm{n}=25)$ \\
\hline Age lyear) & $32.72 \pm 3.43$ \\
V-point & \\
Density $\left(\mathrm{n} / \mathrm{cm}^{2}\right)$ & $79.28 \pm 23.72$ \\
Thickness $(\mu \mathrm{m})$ & $0.089 \pm 0.020$ \\
P-point & \\
Density $\left(\mathrm{n} / \mathrm{cm}^{2}\right)$ & $75.24 \pm 18.79$ \\
Thickness $(\mu \mathrm{m})$ & $0.085 \pm 0.018$ \\
\hline
\end{tabular}

The data is presented as mean \pm standard deviation. poo for 3 months $(\mathrm{P}<0.001)$. The hair density at the V-point improved from $79.28 / \mathrm{cm}^{2}$ at the baseline to $87.56 / \mathrm{cm}^{2}$ after 3 months $(\mathrm{P}=0.866)$, and the hair thickness at the P-point increased from $0.085 \mu \mathrm{m}$ at the baseline to $0.093 \mu \mathrm{m}$ after 3 months $(\mathrm{P}=0.068)$. The latter differences were not statistically significant (Table 2).

After using the shampoo for 1 week (during the follow-up visit at week 1), 10 of the 25 participants complained of minimal to mild

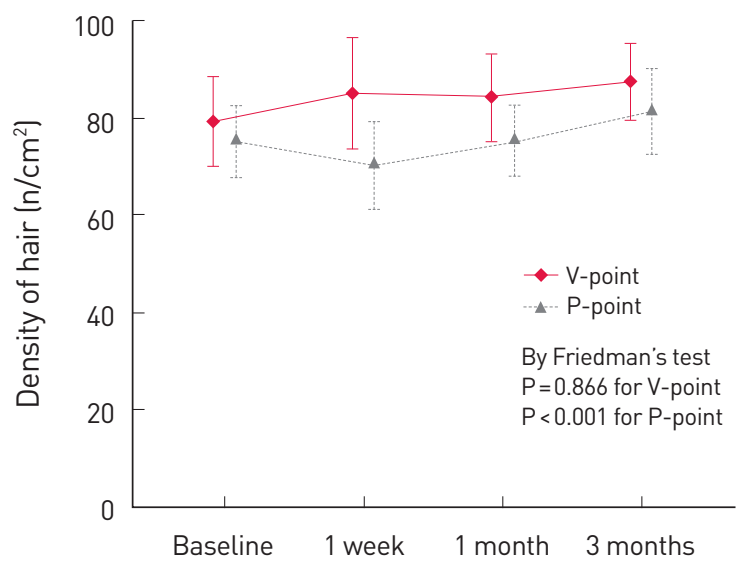

Fig. 2. Results showing improved hair density.

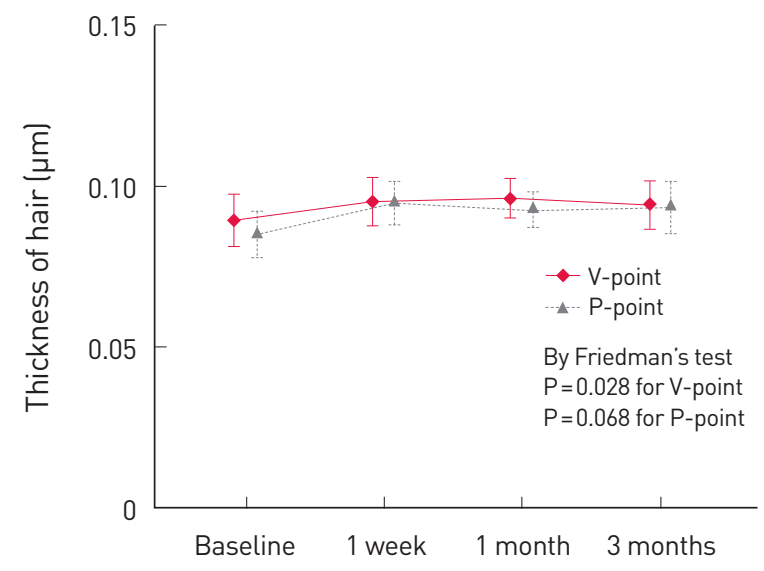

Fig. 3. Results showing improved hair thickness.

Table 2. Change in hair density and thickness

\begin{tabular}{lcccc}
\hline Variable & Baseline $(n=25)$ & At 1 week $(n=25)$ & At 1 month $(n=22)$ & At 3 months $(n=18) \quad$ Comparison $(P$-value) \\
\hline V-point & & & & \\
Density $\left(\mathrm{n} / \mathrm{cm}^{2}\right)$ & $79.28 \pm 23.72$ & $85.12 \pm 29.26$ & $84.23 \pm 21.42$ & $87.56 \pm 16.93$ \\
Thickness $(\mu \mathrm{m})$ & $0.089 \pm 0.020$ & $0.095 \pm 0.019$ & $0.096 \pm 0.014$ & $0.094 \pm 0.016$ \\
P-point & & & & 0.066 \\
Density $\left(\mathrm{n} / \mathrm{cm}^{2}\right)$ & $75.24 \pm 18.79$ & $70.24 \pm 22.80$ & $75.32 \pm 17.11$ & $81.33 \pm 19.31$ \\
Thickness $(\mu \mathrm{m})$ & $0.085 \pm 0.018$ & $0.095 \pm 0.017$ & $0.092 \pm 0.014$ & $0.093 \pm 0.017$ \\
\hline
\end{tabular}

The data is presented as mean \pm standard deviation.

$\mathrm{P}$-values were calculated using the Friedman test. 
Table 3. Safety

\begin{tabular}{lcccc}
\hline Variable & $\begin{array}{c}\text { At } 1 \text { week } \\
(\mathrm{n}=25)\end{array}$ & $\begin{array}{c}\text { At } 1 \text { month } \\
(\mathrm{n}=22)\end{array}$ & $\begin{array}{c}\text { At 3 months } \\
(\mathrm{n}=18)\end{array}$ & $\begin{array}{c}\text { Comparison } \\
\text { (P-value) }\end{array}$ \\
\hline $\begin{array}{l}\text { VAS score (10 points) } \\
\text { Discomfort }\end{array}$ & $1.08 \pm 1.80$ & $0.86 \pm 2.21$ & $1.28 \pm 2.63$ & 1 \\
Yes & & & & \\
No & $10(40.00 \%)$ & $4(18.18 \%)$ & $6(33.33 \%)$ & 0.459 \\
Local response (5 points) & $15(60.00 \%)$ & $18(81.82 \%)$ & $12(66.67 \%)$ & \\
\hline
\end{tabular}

The data is presented as mean \pm standard deviation for continuous variables or number (\%) for categorical variables.

P-values were calculated using the Friedman test for the VAS score and the Cochran's $Q$ test for discomfort.

VAS, visual analog scale.

pain, 7 (44\%) complained of an itchy scalp and dry hair, 2 (13\%) reported a feeling of incomplete cleaning, and $1(6 \%)$ reported that the amount for 1-time use was not sufficient, the skin was itchy, that a considerable amount of dandruff was produced, or that inadequate lather formation caused a feeling of roughness. After using the shampoo for a month (at the 1-month follow-up visit), 5 and 4 of the 22 participants complained of pain and discomfort, respectively; at the 3-month follow-up visit, 4 and 6 of the 18 participants complained of pain and feelings of discomfort such as itching and slipperiness, respectively (Table 3 ).

When the participants rated their degrees of satisfaction with the shampoo and the tonic on a scale of 1 to 5 points, scent received 3.22 points, the feeling of refreshment received 3.87 points, shininess of the hair received 2.78 points, hair elasticity received 3.13 points, and residual scent received 3.00 points. High scores for the feeling of refreshment and hair elasticity were observed. When asked about the degree of lather formation, 16 participants (69.57\%), 6 participants (26.09\%), and 1 participant (4.35\%) responded that it was less than that of other shampoos, similar to that of other shampoos, and greater than that of other shampoos, respectively. When asked about the extent of hair loss before and after giving birth, 2 participants (8.70\%), 12 participants (52.17\%), and 9 participants (39.13\%) responded that it was more severe before giving birth than after, similar before and after, and more severe after giving birth, respectively. It was similar before and after giving birth in a majority of the participants, but a significant number of participants subjectively felt that the degree of hair loss became worse after delivery. The degree of satisfaction with the scent of the tonic received 3.35 points, the overall hair condition received 3.26 points, and the remaining oil content received 3.17 points; a tendency towards overall satisfaction was observed (Table 4). There were no results to show the relationship between the effect of these hair care products and geographical data.

\section{DISCUSSION}

Table 4. Satisfaction of all subjects

\begin{tabular}{lc}
\hline Variable & Total $(\mathrm{n}=25)$ \\
\hline Shampoo & $3.22 \pm 0.90$ \\
Scent & $3.87 \pm 1.06$ \\
Refreshment & $2.78 \pm 1.24$ \\
Shine of hair & $3.13 \pm 1.10$ \\
Elasticity of hair & $3.00 \pm 1.04$ \\
Left scent & \\
Lather & $16(69.57 \%)$ \\
$\quad$ Less & $6(26.09 \%)$ \\
$\quad$ Regular & $1(4.35 \%)$ \\
$\quad$ More & \\
Level of hair loss & $2(8.70 \%)$ \\
$\quad$ Severe before birth & $12(52.17 \%)$ \\
Similar & $9(39.13 \%)$ \\
Severe after birth & \\
Tonic & $3.35 \pm 0.71$ \\
Scent & $3.26 \pm 0.75$ \\
Hair condition & $3.17 \pm 0.83$ \\
Left oil & \\
\hline
\end{tabular}

The data is presented as mean \pm standard deviation for continuous variables or number (\%) for categorical variables.

In this study, a shampoo and a tonic in which the main material was PIGF derived from horses and combined with various materials such as pumpkin extract, panthenol, and niacinamide, were clinically applied. The results showed that no cases of significant hair loss occurred, that the hair thickness at the V-point improved from $0.089 \mu \mathrm{m}$ at the baseline to $0.094 \mu \mathrm{m}$ after 3 months of using the shampoo $(\mathrm{P}=0.028)$, and that the hair density at the P-point significantly increased from $75.24 / \mathrm{cm}^{2}$ at the baseline to $81.33 / \mathrm{cm}^{2}$ after using the shampoo for 3 months, which suggests that this product may have a significant effect on postpartum hair loss and accelerate the recovery period, which takes 6 months in physiological postpartum conditions. Further, no complications other than minor ones such as itching and mild pain were reported by the patients.

The dermal papillae (DP) are a particular type of mesenchymal cells located at the bottom of the hair follicles and play a key role in hair formation [12]. PIGF acts on the DP to increase the hair thickness, accelerate hair growth, and significantly extend the anagen phase of hair growth. Moreover, a previous report stated that PIGF increases the level of phosphorylated extracellular signal-regulated kinase (ERK) and cyclin D1, leading to prevention of cell death, and upregulates phosphorylated Akt and B-cell lymphoma 2 (Bcl2 ) to improve cell survival $[7,13,14]$. Thus far, no clinical trials on how topical PIGF affects the hair follicle or penetrates the epidermis have been reported. Sundaram et al. [15] suggested that some growth factors can penetrate the epidermal layer when applied 
topically.

Horse placenta, which is the main constituent of PIGF, is the most similar tissue to human placenta and is enriched with many growth factors and nutrients, such as amino acids, active peptides, proteins, nucleic acids, vitamins, enzymes, carbohydrates, lipids, and minerals [16]. If it acts on the scalp in a similar fashion as human placenta derivatives do, it may improve the hair thickness and increase the hair density and lifespan. Several papers on PIGF have reported it to have a significant beneficial effect on hair loss $[7,17,18]$.

The overexpression of PIGF strongly increases angiogenesis and vascular permeability. Further, novel blood vessel formation is observed around the hair follicles, with a concomitant upregulation of vascular endothelial growth factor (VEGF). A recent study showed that PIGF increased the average area of blood vessels, which suggests that PIGF plays an important role in hair growth. Further, a significant increase in the mRNA expression of insulin-like growth factor 1, hepatocyte growth factor, and VEGF was argued to stimulate hair growth following PIGF treatment. In contrast, the level of transforming growth factor beta 1 , which inhibits hair growth, was not reduced [7].

Another study demonstrated that PIGF increased the survival of endothelial cells through the expression of anti-apoptotic genes [19]. Further, the expression of Bcl-2 increased in human dermal microvascular endothelial cells and, as a result, the cell viability improved. A western blot analysis confirmed that PIGF increased the expression of $\mathrm{Bcl}-2$, which is responsible for the survival function [20]. Moreover, PIGF treatment was found to enhance cell viability and prevent cell death by increasing the protein activity of cyclin D1 and the phosphorylation of ERK and Akt [7].

During pregnancy, the increased estrogen prevents hair loss by binding to the local estrogen receptors on the hair follicles, which affects their growth and normal cycle. After delivery, the estrogen level returns to normal. This state, characterized by low estrogen levels and excess androgens, promote increased hair shedding and loss, and is known as androgenetic alopecia [3,4].

Cho et al. [8] suggested that pumpkin extract blocks the action of 5-alpha reductase and has antiandrogenic effects on rats [21,22]. In clinical trials, after 24 weeks of treatment, the self-rated improvement score in the pumpkin extract group was higher than in the placebo group. The pumpkin extract group had more hair after treatment at the baseline than the placebo group $(\mathrm{P}<0.001)$. The mean hair count improved by $40 \%$ in the pumpkin extract group at 24 weeks [8].

Schwartz et al. [9] attempted to treat thinning hair and examine the ability of a novel leave-on technology combination (panthenol, niacinamide, and caffeine) to affect the diameter and behavior of individual terminal scalp hair fibers. It yielded an increase in the cross-sectional area of approximately $10 \%$. It also increased suppleness/pliability and resulted in better break stress.

In this study, a shampoo and a tonic containing a combination of PIGF, pumpkin extract, panthenol, and niacinamide were applied in actual clinical cases. This study is significant in that the hair thickness and density significantly improved compared with the baseline before delivery. Further, no notable adverse events were reported; thus, the safety of this product was demonstrated. However, there are certain limitations to this study. While some cases of postpartum hair loss may progress to persistent hair loss, in most cases, the hair will be physiologically restored to the baseline level. Further, the study lacks comparative results using a control group that did not use this combination hair product. The small sample size and the short study period are other limitations. A comparison between two groups is necessary in future, larger-scale, and long-term studies. Moreover, the effect of the combination of PIGF and other materials on different types of hair loss other than postpartum hair loss should be studied.

\section{PATIENT CONSENT}

Patients provided written consent for the use of their images.

\section{REFERENCES}

1. Alonso L, Fuchs E. The hair cycle. J Cell Sci 2006;119:391-3.

2. Mirallas O, Grimalt R. The postpartum telogen effluvium fallacy. Skin Appendage Disord 2016;1:198-201.

3. Piérard-Franchimont C, Piérard GE. Alterations in hair follicle dynamics in women. Biomed Res Int 2013;2013:957432.

4. Hadshiew IM, Foitzik K, Arck PC, et al. Burden of hair loss: stress and the underestimated psychosocial impact of telogen effluvium and androgenetic alopecia. J Invest Dermatol 2004;123:455-7.

5. Malkud S. A Hospital-based study to determine causes of diffuse hair loss in women. J Clin Diagn Res 2015;9:Wc01-4.

6. Eastham JH. Postpartum alopecia. Ann Pharmacother 2001;35:255-8.

7. Yoon SY, Yoon JS, Jo SJ, et al. A role of placental growth factor in hair growth. J Dermatol Sci 2014;74:125-34.

8. Cho YH, Lee SY, Jeong DW, et al. Effect of pumpkin seed oil on hair growth in men with androgenetic alopecia: a randomized, double-blind, placebo-controlled trial. Evid Based Complement Alternat Med 2014; 2014:549721.

9. Schwartz J, Gemmer C, Krigbaum H, et al. Scalp care efficacy of a leaveon treatment based on niacinamide, caffeine, and panthenol. J Am Acad Dermatol 2014;5:AB54.

10. Lee BS, Chan JY, Monselise A, et al. Assessment of hair density and caliber in Caucasian and Asian female subjects with female pattern hair loss by using the Folliscope. J Am Acad Dermatol 2012;66:166-7.

11. Mubki T, Rudnicka L, Olszewska M, et al. Evaluation and diagnosis of the hair loss patient: part II. Trichoscopic and laboratory evaluations. J Am Acad Dermatol 2014;71:431.e1-.e11.

12. Inui S, Fukuzato $Y$, Nakajima $\mathrm{T}$, et al. Androgen-inducible TGF-beta1 from balding dermal papilla cells inhibits epithelial cell growth: a clue 
to understand paradoxical effects of androgen on human hair growth. FASEB J 2002;16:1967-9.

13. Odorisio T, Cianfarani F, Failla CM, et al. The placenta growth factor in skin angiogenesis. J Dermatol Sci 2006;41:11-9.

14. Yano K, Brown LF, Detmar M. Control of hair growth and follicle size by VEGF-mediated angiogenesis. J Clin Invest 2001;107:409-17.

15. Sundaram H, Mehta RC, Norine JA, et al. Topically applied physiologically balanced growth factors: a new paradigm of skin rejuvenation. J Drugs Dermatol 2009;8:4-13.

16. Seo HS, Lee DJ, Chung JH, et al. Hominis Placenta facilitates hair regrowth by upregulating cellular proliferation and expression of fibroblast growth factor-7. BMC Complement Altern Med 2016;16:187.

17. Cianfarani F, Zaccaria ML, Odorisio T, et al. Expression of placenta growth factor in mouse hair follicle cycle. G Ital Dermatol Venereol 2005;140:497-503.
18. Mecklenburg L, Tobin DJ, Müller-Röver S, et al. Active hair growth (anagen) is associated with angiogenesis. J Invest Dermatol 2000;114: 909-16.

19. Adini A, Kornaga T, Firoozbakht F, et al. Placental growth factor is a survival factor for tumor endothelial cells and macrophages. Cancer Res 2002;62:2749-52.

20. Nör JE, Christensen J, Mooney DJ, et al. Vascular endothelial growth factor (VEGF)-mediated angiogenesis is associated with enhanced endothelial cell survival and induction of Bcl-2 expression. Am J Pathol 1999;154:375-84.

21. Esfandiari A, Kelly AP. The effects of tea polyphenolic compounds on hair loss among rodents. J Natl Med Assoc 2005;97:1165-9.

22. Carbin BE, Larsson B, Lindahl O. Treatment of benign prostatic hyperplasia with phytosterols. Br J Urol 1990;66:639-41. 